\title{
THESIS
}

\section{CHARACTERIZATION OF CO-BENEFITS OF GREEN STORMWATER INFRASTRUCTURE ACROSS ECOHYDROLOGIC REGIONS IN THE UNITED STATES}

\author{
Submitted by \\ William Rainey \\ Department of Civil and Environmental Engineering \\ In partial fulfillment of the requirements \\ For the Degree of Master of Science \\ Colorado State University \\ Fort Collins, Colorado
}

Fall 2020

Master's Committee:

Advisor: Mazdak Arabi

Sybil Sharvelle

Melissa McHale 
Copyright by William Rainey 2020

All Rights Reserved 
ABSTRACT

\section{CHARACTERIZATION OF CO-BENEFITS OF GREEN STORMWATER INFRASTRUCTURE ACROSS ECOHYDROLOGIC REGIONS IN THE UNITED STATES}

Green stormwater infrastructure (GSI) systems such as rain gardens, permeable pavement and bioswales are commonly used in municipalities to reduce urban flooding and water pollution. In conjunction with these direct benefits, GSI systems provide additional social and ecological "cobenefits". Our goal was to investigate the co-benefits of commonly used GSI systems in five cities in the United States, including Baltimore, Denver, New York City, Philadelphia, and Portland. Specifically, carbon storage, carbon sequestration, air pollution removal, UV reduction, and cooling effects of the trees used in GSI in the study cities were quantified. The i-Tree Eco urban forestry model was used to predict various co-benefits for individual tree species and total SGI tree inventories across the five study cities based on observed tree characteristic data. Aspects of SGI design, environmental factors, and model inputs were evaluated to find what influences the assessment of SGI co-benefits.

SGI design types and utilization levels of those designs played a big role in determining the number of trees used in SGI projects, however there is more nuance to the evaluation of co-benefits of different cities' SGI trees than just the tree population. Climate was a large influence on co-benefits' estimation, with similar co-benefit responses for cities with similar climates, like the eastern seaboard. The inputs that influence co-benefit predictions the most were evaluated using global sensitivity analysis. We also found that the inputs that represent the tree growth and environmental factors heavily influenced the computation of co-benefits in i-Tree Eco. Our research supports current literature in developing SGI programs that provide the most amount of co-benefits for specific climates. This study aims to reveal more about the mechanisms and prevailing equations within i-Tree Eco by providing modelled datasets and assessment approaches to estimate the co-benefits of GSI at unit and city levels. 


\section{ACKNOWLEDGEMENTS}

I am appreciative for the help and support that I have received to complete my degree and research. I would like to thank Dr. Mazdak Arabi for his leadership benefitting this project, as well as contributing to the advancement of my academic and professional career. Thank you for your support throughout these past two years. I would like to thank the National Science Foundation Sustainability Research Network Cooperative Agreement \#1444758 for supporting this study. Additionally, I want to thank my committee members, Dr. Sybil Sharvelle and Dr. Melissa McHale for their expertise and input, as well as everyone in 119 Glover who have offered advice and help.

Finally, I am grateful for my friends and family for the love and support that they have given me during this endeavor. The friends I've made at during my time here at Colorado State University have opened my eyes to new perspectives and experiences by providing valuable advice and exploring the natural areas of Colorado. I am appreciative for my wonderful family. Thank you Mom, Dad, and Jackson for helping me become the person I am today. 


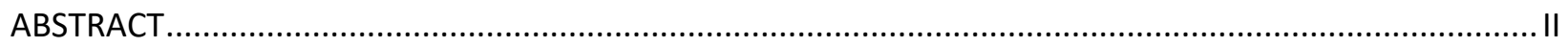

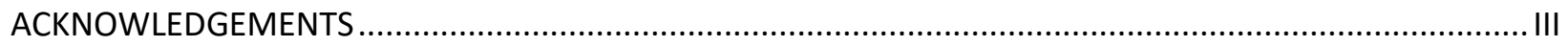

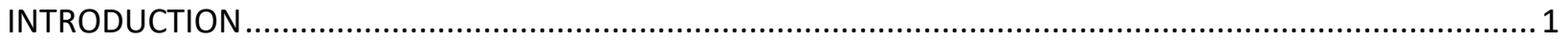

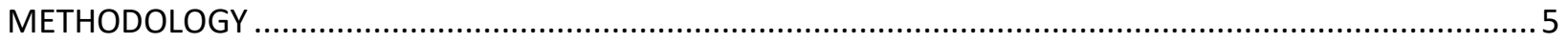

Urban Tree Dataset for Green Infrastructure in Each City ................................................. 5

Datasets of Observed Urban Tree Species in the Study Cities............................................. 6

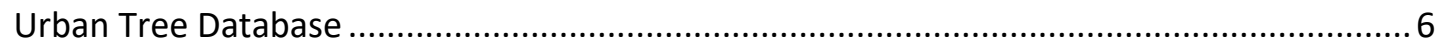

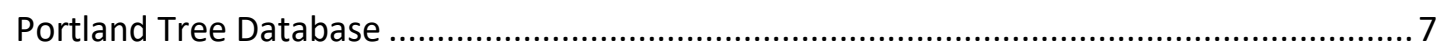

Botanical Information and Ecology Network (BIEN) Database ........................................... 7

Reorientation of Tree Characteristics in the Study Cities ................................................ 8

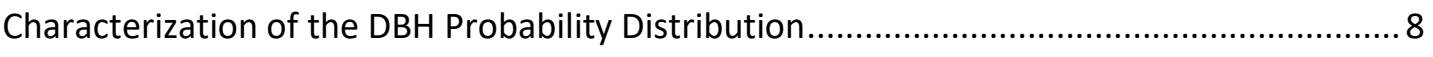

Modelling Crown Height, Tree Height, and Crown Width ............................................. 8

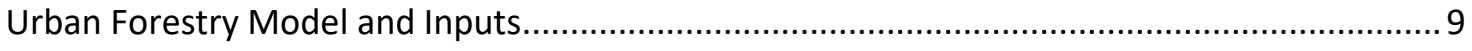

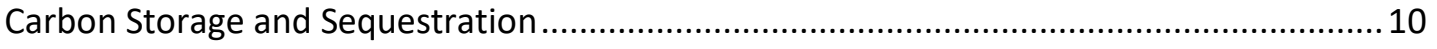

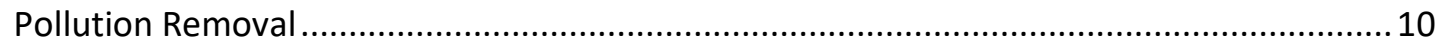

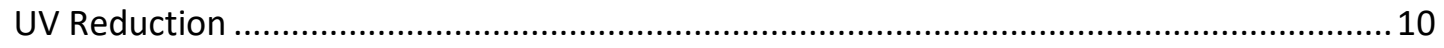

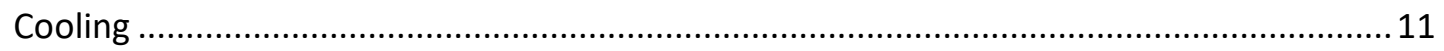

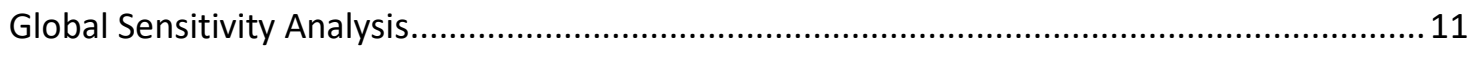

Corroboration of the Validity of the Probabilistic Assessments ......................................... 12 
Design.

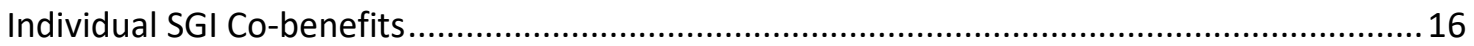

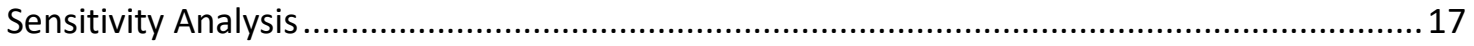

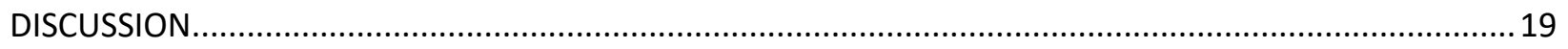

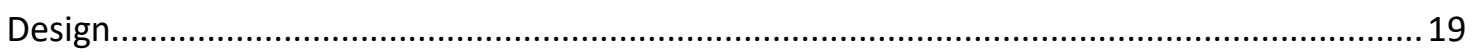

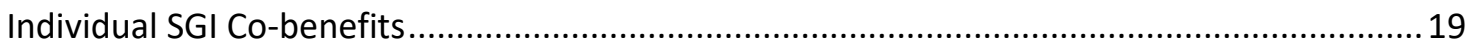

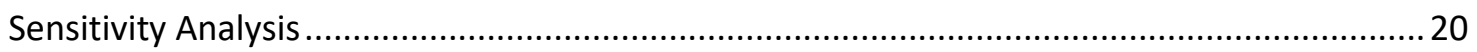

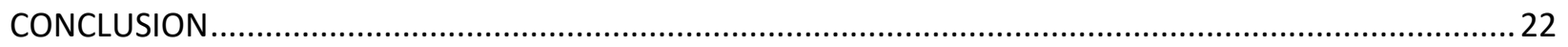

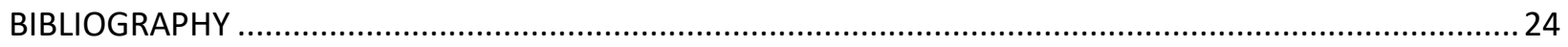




\section{INTRODUCTION}

Urbanization has led to a myriad of regional environmental challenges like increased stormwater runoff, water quality pollution, urban heat, and air pollution (Duh et al., 2008; Shortle et al., 2020; Tam et al., 2015; Tasdighi et al., 2017). Cities also contribute to the global climate change with increased energy consumption and greenhouse gas emissions (Corfee-Morlot, 2011; Grimm et al., 2008). Climate change compounds the adverse environmental impacts of urbanization and population on the vulnerability of city's existing infrastructure to extreme events (Neumann et al., 2015). Cities increasingly rely on adaptation strategies to improve social, ecological, and technological resiliency to changes in climate, land use, population, and economy (Daigger et al., 2020; Rosenzweig et al., 2011).

To alleviate their flooding problems, cities continue to invest in stormwater infrastructure which uses storage capacity to capture excessive water runoff during intense storms by integrating conveyance and infiltration to provide flood control for cities (Porse, 2013). Two primary types of stormwater infrastructure technologies are used to manage urban stormwater, namely grey infrastructure and green infrastructure. Grey infrastructure systems are constructed units that provide storage for stormwater, such examples include wastewater treatment plants, pipelines, and reservoirs. The Clean Water Act defines Green Stormwater Infrastructure (GSI) to be a wide range of technologies that manage water by using permeable surfaces and landscaping to "store, infiltrate, or evaporate stormwater and reduce flows to sewer systems"(UESPA, 2020). GSI use vegetated surfaces in bioretention areas to capture water. GSI has shown to be as effective as grey systems in reducing peak flows and more cost effective than grey systems (USEPA, 2013a; Vineyard et al., 2015). In many cases, GSI have been found to provide improved additional ecological and social co-benefits that are not achieved by traditional grey infrastructure (Jim et al., 2015; Young et al., 2011). Green infrastructure 
systems increase groundwater infiltration and change the urban hydrologic cycle. These systems can reduce flows into sewer collection systems, and subsequently diminish sewer overflows.

Trees are commonly used as the primary vegetation in GSI because of their large water carrying capacity (Litvak et al., 2012; McCarthy et al., 2011). Trees used in GSI can enhance the performance of GI by providing water control benefits, removing air pollution (Mcpherson et al., 1997; Yang et al., 2005), cooling of surrounding areas (Livesley et al., 2016; Sanusi et al., 2017), and reducing UV exposure (Heisler and Grant, 2000), as well as providing many other benefits (McPherson et al., 1997). These studies show the benefits of specific trees species in certain cities. Few studies have focused specifically on all the benefits of trees associated with SGI across the triple bottom line.

Various SGI systems are implemented as distributed systems in cities, which include tree trenches, rain gardens, vegetated swales, wetlands, infiltration planters, vegetated median strips, reforestation, and protection and enhancement of riparian buffers and floodplains (Wise et al., 2010). These systems have different sizes and thus different capabilities for vegetation. Small scale SGI like rain gardens and tree trenches will have small amounts of trees per unit. Large scale SGI like wetlands and swales can have more amounts of trees per unit due to their expansive detention basins. Green systems and urban forests have a number of other environmental and economic benefits in addition to reducing the volume of sewer overflows and stormwater discharges, including improved air quality (Peng and Jim, 2015; Wise et al., 2010); reduced urban heat island effects (Meerow and Newell, 2017; Tzoulas et al., 2007); increased energy savings (Spatari et al., 2011; Staddon et al., 2018); community benefits(Coutts and Hahn, 2015; Gallet and Grant, 2010); and infrastructure construction and maintenance cost savings(Foster et al., 2011; Vineyard et al., 2015). All these externalities of GSI are referred as cobenefits. 
Co-benefits of GSI may be evaluated using a triple bottom line framework which categorize the benefits in terms of economic, environmental and social benefits (Hammer and Pivo, 2016). Many cities have investigated ways to characterize the benefits of different GSI approaches in general guidelines (USEPA, 2013.; Portland, 2010; UMD, 2017). Different approaches have been suggested to quantify cobenefits of stormwater infrastructure, including the use of the Normalized Difference Vegetation Index (Spahr et al., 2020) and allometric equations under different management strategies (Alves et al., 2019; Zhan et al., 2016). Previous studies have also investigated the co-benefits provided by specific technologies such as green roofs (Peng and Jim, 2015) and constructed wetlands (Stefanakis, 2019). These studies focus on the effects of green infrastructure vegetation on various co-benefits, however there are no studies that have looked at how the different designs of SGI technologies change the scale of co-benefits provided by a municipal scale SGI program.

One of the most extensive models of tree benefit evaluation is the i-Tree model suite, formerly known as the Urban Forest Effects Model (Nowak and Crane, 2000). The i-Tree model suite is a software developed by the U.S. Forest Service and is widely used by urban planners to quantify the ecosystem services of urban trees (Nowak, 2016; Nowak et al., 2000). The model calculates different effects including carbon sequestration, air pollutant removal and cooling from allometric equations developed for a wide variety of trees (McPherson and Simpson, 1999; Nowak et al., 2006). The process-based model incorporates climatic and ecological conditions along with tree species and characteristics to represent ecohydrological processes (Nowak et al., 2008a). However, modeling uncertainties in the estimated effects of trees across ecohydrological regions have not been adequate characterized.

The prediction uncertainty in i-Tree simulations is influenced by the sampling error, which is a function of the total number of trees within study area (Nowak et al., 2008b). Moreover, Model structure uncertainty in the allometric equations contribute to the uncertainty in predictions (Nowak et 
al., 2013). To better understand the uncertainty associated with i-Tree, studies have looked at developing sensitivity analyses on i-Tree mechanisms using the Morris one-at-a-time method (Hirabayashi et al., 2011; Lin et al., 2020). However, this technique is a local method and only reveals the main effects of parameters but cannot quantify the importance of interactions between model parameters. On the other hand, global sensitivity analysis can quantify the main and interactions effects of model parameters (Marino et al., 2009; Saltelli, 2008). Few studies have used global sensitivity analysis methods to identify the effects of uncertainty in i-Tree parameters and model structure on the estimated co-benefits (Hirabayashi et al., 2011; Lin et al., 2020). Studies have shown the co-benefits of specific SGI technologies (Gallet and Grant, 2010), some using i-Tree Eco(Jayasooriya et al., 2017; Kim et al., 2015). Particularly, the co-benefits (and associated uncertainties) of trees that are implemented in GSI in cities across ecohydrological conditions have not been studied fully.

This study investigates the co-benefits of trees used in Stormwater Green Infrastructure (SGI) programs across different ecohydrologic regions in the US. We utilized the i-Tree Eco model, a popular model implemented in the urban forestry literature, to predict the co-benefits of SGI programs in five U.S. cities: Baltimore, Denver, New York City, Philadelphia, and Portland. Our first goal was to analyze a variety of SGI designs implemented across cities and evaluate how the number of trees and their associated co-benefits vary with the typology of designs. Second, in order to also understand the role of general environmental factors, or native biome, as used in the i-Tree Eco model, the development of cobenefits of SGI trees will be compared by the co-benefits provided by one single tree, of the same species, among multiple cities. Finally, we explore a variety of other attributes of the i-Tree Eco model to better understand what factors, or variable inputs in the model, have the most influence on the cobenefit evaluation of trees in SGI projects. Overall, these results will impact how SGI projects are both designed and studied in cities. We conclude with some recommendations on planning SGI projects to maximize the co-benefits provided to urban residents. 


\section{METHODOLOGY}

We compiled a comprehensive database of GSI locations and infrastructure types for Denver, Portland, New York City, Philadelphia, and Baltimore. Urban tree databases were used to obtain tree species and characteristics in each region. We then used the i-Tree urban forestry model to simulate the effects of trees on greenhouse gas (GHG) emissions, carbon sequestration, and other responses. The importance of $\mathrm{i}$-Tree model inputs on co-benefits was evaluated using the extended Fourier Amplitude Sensitivity Test (eFAST) global sensitivity analysis. The analysis also revealed important tree characteristics that influence various tree effects estimated by the i-Tree model. The co-benefits are aggregated at the municipal level using the GSI database for each city.

\section{Urban Tree Dataset for Green Infrastructure in Each City}

The GSI location and types in Denver, Portland, New York City, Philadelphia, and Baltimore were obtained. The study cities represent various climatic regions and utilize different vegetation in their green infrastructure plans. The stormwater management manual for each city were found through the city's official Water Department websites ( City of Philadelphia Water Department, 2014; City of Portland, 2016; Denver, 2016; State, 2010; State of Maryland, 2009a). The manuals described the types of infrastructure interventions that are used to divert, contain, and slow the amount of stormwater runoff going through the city's stormwater infrastructure systems. Each city had different considerations based on geography, storm frequency, rainfall intensity, and other factors. Cities on coasts, like Baltimore, are required to provide treatment to runoff before draining effluent into large bodies of water(City of Baltimore, 2013). Arid cities such as Denver, must have its GSI adhere to detention regulations by draining all captured water within 72 hours (The City and County of Denver Public Works, 2016) . 
We reviewed each city's design manual to find the trees used in GSI technologies (City of Portland, 2016; NYCDEP, 2013; Philadelphia Water Department, 2018; State of Maryland, 2009b; The City and County of Denver, 2017). The GSI technologies that utilized trees include rain gardens, green streets, extended detention basin, and bioswales. For Philadelphia and New York, the frequency of tree species used were represented by probabilistic tree species models for each to better predict the benefits of planted trees (NYCDEP, 2018a; Philadelphia Water Department, 2020). We assumed the distribution of tree species were uniform for all other cities.

The total number of trees used in all GSI was determined through inspection of design manuals to find the unit area of SGI and then using spatial datasets to find the total number of SGI projects that use trees.

\section{Datasets of Observed Urban Tree Species in the Study Cities}

We collected databases of tree species for each city to accurately represent tree characteristics. Tree characteristic information included diameter at breast height (DBH), tree height, base of crown height, and crown width. DBH is the measured width of the tree trunk at 1.3 meters above the ground. Tree height is the distance from the ground to the top of the tree. The base of the crown height is the distance from the ground until the first major branch of the tree. Crown width is the distance from one end of foliage to the other end of foliage. These factors influence carbon sequestration, air quality improvement and other effects of tree species and were used as inputs in the modeling assessments.

\section{Urban Tree Database}

The Urban Tree Database (UTM) provided collected tree characteristic data including DBH, tree height, base of crown height and crown width and specific tree growth equations for trees in different urban regions (McPherson et al., 2016). 
For each city in this study, we chose a representative city from UTM except for Portland, which has its own comprehensive tree database. Growth relationships for tree species that grow in more than one region were represented by different equations to reflect heterogeneity in climate and management. Table 1 describes the databases used for each city.

Table 1: City Tree Databases for Portland, Philadelphia, Baltimore, New York City, and Denver

\begin{tabular}{|l|l|l|}
\hline \multicolumn{1}{c}{ City } & \multicolumn{2}{c|}{ Database } \\
\hline Portland, Oregon & City of Portland Tree Inventory & N/A \\
\hline Philadelphia, Pennsylvania & Urban Tree Database & $\begin{array}{l}\text { Charlotte, North Carolina and New } \\
\text { York City, New York }\end{array}$ \\
\hline Baltimore, Maryland & Urban Tree Database & Charlotte, North Carolina \\
\hline New York City, New York & Urban Tree Database & New York City, New York \\
\hline Denver, Colorado & Urban Tree Database & Fort Collins, Colorado \\
\hline
\end{tabular}

\section{Portland Tree Database}

The city of Portland's Tree Inventory Project has tree characteristic data available for 25,000 trees ((City of Portland, 2017, Portland Parks \& Recreation, 2020). This dataset is more robust and comprehensive than the data in UTM. ).

\section{Botanical Information and Ecology Network (BIEN) Database}

The Botanical Information and Ecology Network (BIEN) is a comprehensive botanical database with 915,000 trait observations globally (Maitner et al., 2018). BIEN was accessed to find georeferenced observations of the tree species utilized in each city. For most of the trees in this study, more DBH data was available through BIEN than UTM. Improved representation of DBH, which is a critical indicator for tree growth (McPherson and Mori, 1998), enhanced the estimated effects of tree species using the iTree model. 


\section{Reorientation of Tree Characteristics in the Study Cities}

To create a better representation of estimation of tree characteristics, we developed models and equations to represent the relationships in raw tree characteristic data found in the tree databases.

\section{Characterization of the DBH Probability Distribution}

Observed tree characteristics vary within each region due to soils, local climate, management, and other factors. Probability distributions were used to represent the uncertainty in tree characteristics for each species in each region. The normal, lognormal, Weibull, gamma and exponential distributions were considered to fit to the observed DBH data using the maximum likelihood estimator method in MATLAB (Mathworks ${ }^{\circledR}$ ). The goodness of fit of the distributions were examined using graphical evaluation of the observed and theoretical cumulative distributions, quantile-quantile (QQ) plots, and Kolmogorov-Smirnov tests.

\section{Modelling Crown Height, Tree Height, and Crown Width}

We used nonlinear regression analysis to model Crown Height, Tree Height, and Crown Width as a function of DBH for each species in the UTM dataset. Specifically, a quadratic equation was used. Equation 1 is the form of the log polynomial equations to describe the relationship between $\mathrm{DBH}$ and the specific tree parameter:

$$
\ln (y)=p_{3}+p_{2} \ln (x)+p_{1}[\ln (x)]^{2}
$$

where $y$ denotes the tree parameter of interest (i.e., Tree Height, Crown height, or Crown Width), $x$ represents $\mathrm{DBH}$, and $p_{1}, p_{2}$, and $p_{3}$ are the constant regression model parameters. Parameter estimation was conducted using the "fit" function in MATLAB (Mathworks ${ }^{\circledR}$ ). The Portland data was filtered to remove high $\mathrm{DBH}$ and maximum tree height values because these values for trees in parks are not indicative of the of what is suitable for street use. 


\section{Urban Forestry Model and Inputs}

The i-Tree Eco tool is a modelling software developed by the U.S. Forest Service to quantify the ecosystem services trees can provide to the surrounding areas. These ecosystem services include environmental and economic benefits such as carbon sequestration, air pollutant removal, structural value, Ultraviolet (UV) reduction, oxygen production and other benefits. The i-Tree model has been used by many researchers and urban planners to quantify the benefits of trees over a range of ecohydrologic conditions (Lin et al., 2019)

The i-Tree Eco model input data for each tree included DBH, Tree Height, Crown Base Height, Crown Width, Crown Light Exposure (CLE), Crown Health, and Crown Missing. DBH is a "constant nonreversible feature of tree growth,"(White, 1998) and can be used to estimate the age of trees with modelled growth factor equations specific for each species (Lhotka and Loewenstein, 2011). Thus, DBH represented the age and growth of the tree. CLE is the number of sides of the tree receiving sunlight from above, indicating the amount of light the tree is exposed to. Crown Health is an indicator of the health of the tree based on inspection of dead branches; it is determined as the percent of dieback in the crown volume. Crown Missing represented how full the crown is based on the amount of foliage on the branches, it is the percentage of the crown volume not occupied by branches and leaves (Forest Service, 2020).

The i-Tree model inputs included climate and air quality factors. For each study city, a representative NOAA weather station was chosen to obtain data on local weather and ambient air quality. For energy effects of trees, the distance to the closest building was needed. The spatial datasets for the GSI and building footprints were obtained for each city (Baltimore, 2018; Bell, 2020; Choat, 2020; City of New York, 2020; City of Philadelphia Planning and Research, 2020; City of Philadelphia Water Department, 2020; City of Portland, 2020; NYCDEP, 2018b; The City and County of Denver, 2020, 2016). 
The distance between each tree and the nearest building and the number of trees used in SGI projects were recorded. The distance to the closest building was determined using the spatial analysis tool in ArcGIS (ESRI, 2019). The input data were used to compute carbon storage and sequestration, air pollution removal, UV reduction, and cooling effects of GSI trees.

\section{Carbon Storage and Sequestration}

During photosynthesis, trees are able to capture carbon dioxide and store the carbon as biomass(Nowak et al., 2013). Carbon storage and carbon sequestration calculations in i-Tree Eco came from allometric equations for tree growth, morality, and decomposition (Nowak et al., 2013). Carbon Sequestration comes from growth equations and the resulting annual change in carbon storage (Jo and McPherson, 1995; Nowak, 2010; Nowak et al., 2008a).

\section{Pollution Removal}

i-Tree Eco models weight of air pollutants removed per tree. Pollutants in i-Tree Eco's analysis include carbon monoxide (CO), sulfur dioxide $\left(\mathrm{SO}_{2}\right)$, nitrogen dioxide $\left(\mathrm{NO}_{2}\right)$, ozone $\left(\mathrm{O}_{3}\right)$, and particulate matter less than 2.5 microns $\left(\mathrm{PM}_{2.5}\right)$. Detailed equations were developed to model dry deposition of the criteria pollutants (Hirabayashi et al., 2015).

\section{UV Reduction}

UV radiation is emitted by the sun and can have negative health effects caused by overexposure (USEPA, 2006). The World Health Organization developed the UV index scale to describe the levels of UV radiation to protect people from overexposure (World Health Organization, 2017). i-Tree Eco calculated the reduction in UV radiation the tree canopy provides and reported the results as percent reduction in UV index (Ryeol et al., 2014). 
Cooling

i-Tree calculated the seasonal effects of trees on residential building energy use based on distance and direction of trees from residential structures, tree height and tree condition data (McPherson and Mori, 1998; McPherson and Simpson, 1999).

\section{Global Sensitivity Analysis}

A global sensitivity analysis was conducted to characterize prediction uncertainty and the importance of tree parameters influencing the outputs of the i-Tree model. The extended Fourier Amplitude Sensitivity Test (eFAST) (Saltelli, 2008) was used to characterize the uncertainty in estimated co-benefits from the i-Tree model. Moreover, the importance of model parameters and processes they represent can be evaluated by global sensitivity analysis.

Global sensitivity analysis propagates uncertainty in model parameters to the outputs and reveals the importance of each parameter individually (the main effects) and in interaction with other parameters (total effects) (Lilburne et al., 2006). A sample of 5000 model parameters were generated for each tree species in each city. The i-Tree model simulations were performed for each parameter set and were used to estimate parameter sensitivity indices and prediction uncertainties.

The first-order sensitivity index represents the fraction of the total output variance attributed to a single model parameter. The sum of first-order sensitivity indices may not add up to one, indicating that non-linear interactions also influence model outputs. The total-order sensitivity index for each parameter quantifies the fraction of the total output variance from interactions of the parameter of interest with other model parameters. The Simlab software was used in this study to conduct the global sensitivity analysis (EU Science Hub, 2008). Table 2 presents the model parameters and their probability distributions used in the analysis. The Crown Height, Tree Height, and Crown Width parameters were estimated from the fitted nonlinear regression equations (Eq. 1) for each tree species in each region. 
Table 2: Probability Distributions Types for each Tree Parameter in each City

\begin{tabular}{|c|c|c|}
\hline City & Tree parameters & Distribution Types \\
\hline Portland, Oregon & $\begin{array}{l}\text { DBH, Tree Height, Crown } \\
\text { Height, Crown Base }\end{array}$ & Weibull, Gamma, Lognormal \\
\hline Philadelphia, Pennsylvania & $\begin{array}{l}\text { DBH, Tree Height, Crown } \\
\text { Height, Crown Base }\end{array}$ & Weibull, Gamma \\
\hline Baltimore, Maryland & $\begin{array}{l}\text { DBH, Tree Height, Crown } \\
\text { Height, Crown Base }\end{array}$ & Weibull, Gamma, Lognormal \\
\hline New York City, New York & $\begin{array}{l}\text { DBH, Tree Height, Crown } \\
\text { Height, Crown Base }\end{array}$ & Weibull, Gamma, Lognormal \\
\hline Denver, Colorado & $\begin{array}{l}\text { DBH, Tree Height, Crown } \\
\text { Height, Crown Base }\end{array}$ & Weibull, Gamma, Lognormal \\
\hline
\end{tabular}

Corroboration of the Validity of the Probabilistic Assessments

The performance validity of the i-Tree Eco model and prediction intervals for the co-benefits was assessed using data from the U.S. Forest Service's Community Tree Guides (Mcpherson et al., 2007, $2006,2003,2002)$. These reports quantified benefits and costs of representative trees in various regions in America based on regression equations. 


\section{RESULTS}

Our goal was to analyze a variety of SGI projects implemented in cities across the US to determine the variables that have the most influence on co-benefits provided by trees. The i-Tree Eco tool, a popular urban forestry model, was used to predict SGI co-benefits on the individual and municipal level tree scale.

Design

Denver was dominated by larger SGI technologies such as Detention Ponds and Extended Detention Basins (Figure 1), these infrastructure interventions are large areas dedicated to the temporary impoundment of stormwater runoff. In other cities like New York City, Portland and Philadelphia smaller infrastructure technologies were prevalent, including Rain Gardens, Bioswales and Green Streets (Figure 1). These technologies were often located in the "Right of Way,"(ROW) and were cradled by impervious surfaces like streets and sidewalks. Since ROW SGIs have less expansive area, they don't often use as many trees as the larger detention areas. 


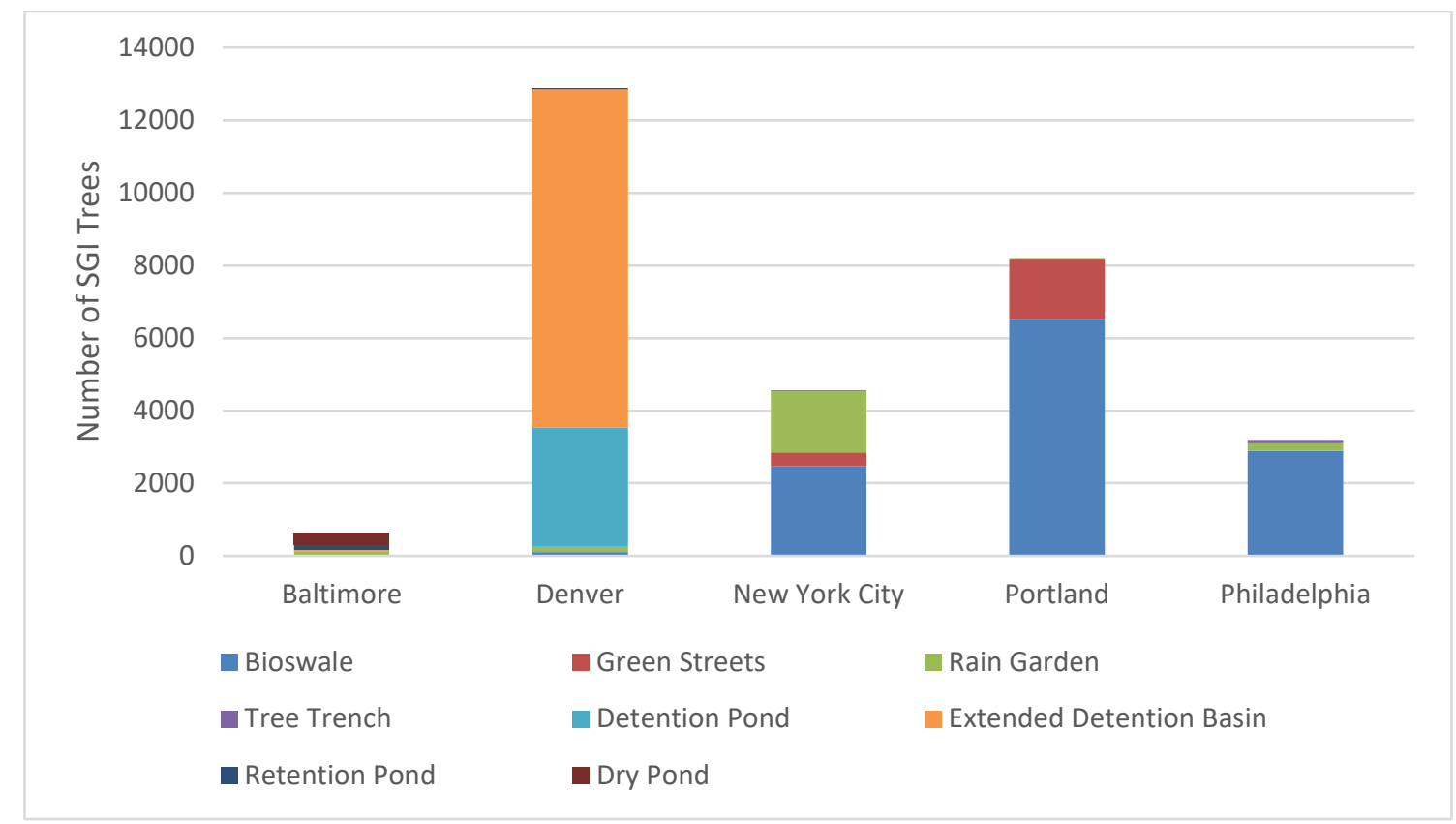

Figure 1: Number of SGI Trees by Technology Type in Each Study City

The aggregation of composite tree benefits on the municipal level showcased the total cobenefits provided to the city by SGI. Denver and Portland had the most expansive use of trees in their SGI programs compared to other cities in the analysis (Figure 1). As a result, the aggregate benefits were higher for Denver and Portland than other cities with smaller tree inventories (Figure 2). 

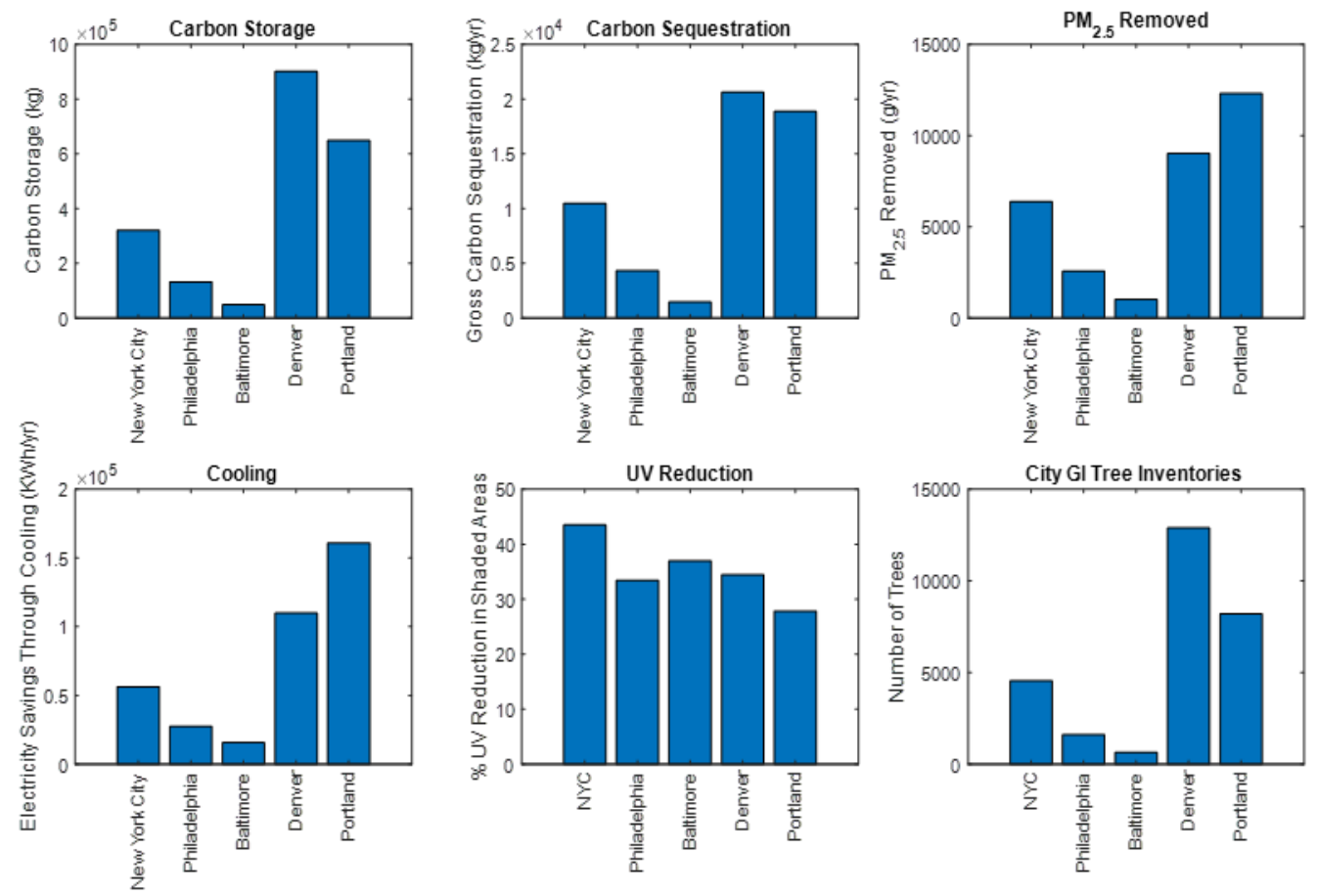

Figure 2: Median Values of Carbon Storage, Carbon Sequestration, PM 2.5 Removal, Cooling, and UV Reduction Municipal Level Co-benefits with the Tree Inventories for the cities of Baltimore, Denver, New York City, Philadelphia, and Portland

Denver had the most amount of Carbon storage and Carbon sequestration co-benefits and Portland has the most amount of $\mathrm{PM}_{2.5}$ and Cooling co-benefits (Figure 2). Despite the fact that Denver had the largest amount of trees, there are other factors, like size of trees and leaf area that also influence the relative amount of co-benefits provided by these projects. The types of SGI designs and utilization levels of those designs may play a big role in determining the number of trees used in SGI projects, however there is more nuance to the evaluation of co-benefits of different cities SGI trees than the tree populations. 
Individual SGI Co-benefits
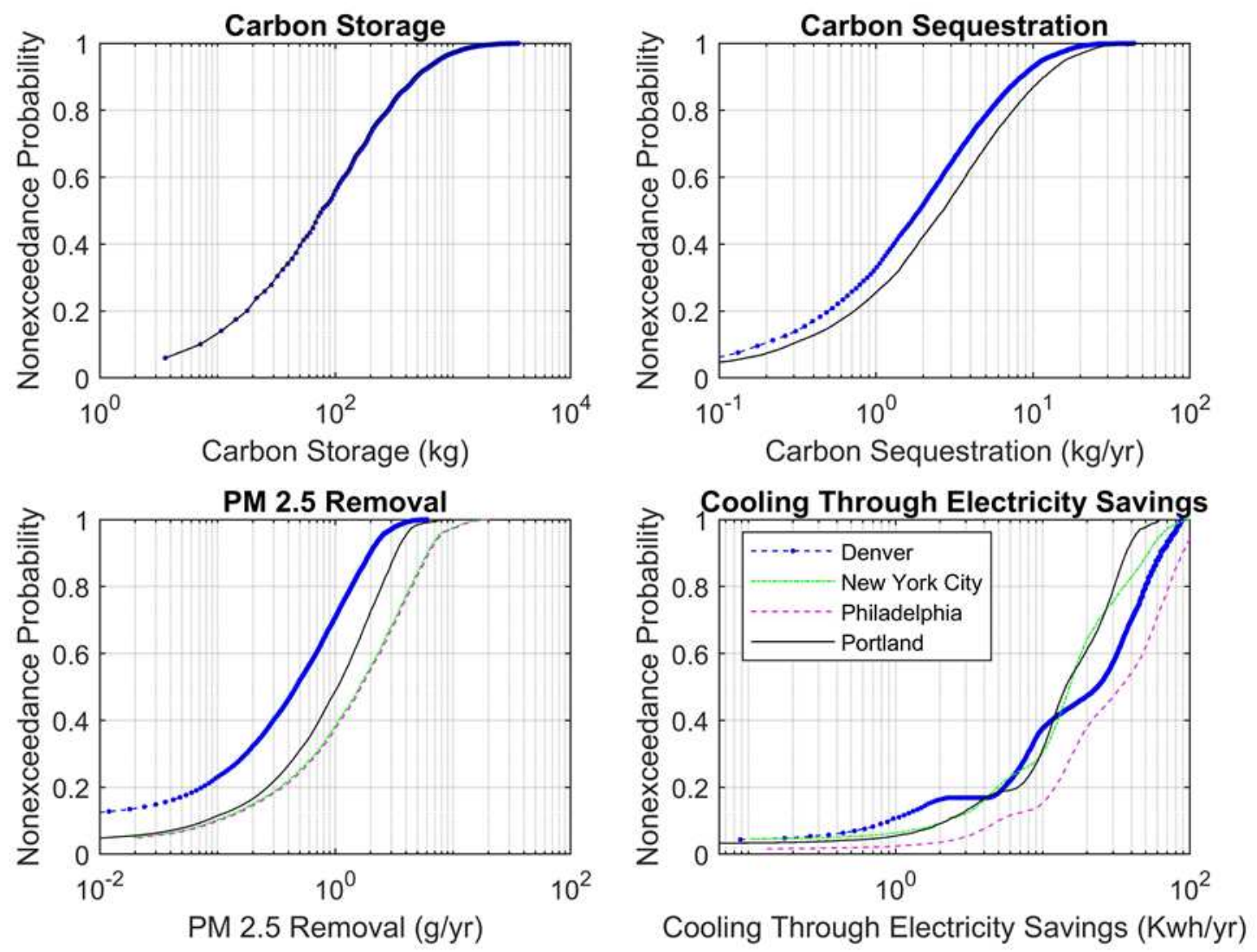

Figure 3: Honeylocust Tree Co-benefits among Study Cities

Honeylocust, Gleditsia triacanthos, was identified as the most common tree species across all of the sites and it was suitable for the SGI in all four cities: Denver, New York City, Philadelphia, and Portland. The Honelylocust tree grow differently based on regional growth data of Honeylocust tree characteristics in the study cities.

The results from the carbon storage analysis revealed that the four cities had similar cumulative distribution curves (Figure 3). Carbon sequestration and $\mathrm{PM}_{2.5}$ removal co-benefits showed that Denver experienced lower levels of carbon sequestration and pollutants removed than other cities on the per tree basis (Figure 3). The model results convey that the eastern seaboard cities of New York City and Philadelphia had the largest amounts of $\mathrm{PM}_{2.5}$ removal associated with trees, followed by Portland. All 
the cities had similar amounts of electricity savings through cooling with the same relative response curves (Figure 3) with Philadelphia having the most amount of cooling co-benefits followed by Denver.

The individual composite tree co-benefits show that different cities' composite trees excel at different co-benefits (Appendices I and J). Denver's co-benefits are shown to have sharper CDFs than other cities which indicates lesser amounts of co-benefits including $\mathrm{PM}_{2.5}$ removal, cooling and carbon sequestration. Particularly, NYC, Baltimore and Philadelphia have closely aligned CDFs and boxplots.

Despite having the largest inventory of SGI trees, Denver performs the least well for some select co-benefits. Another trend seen is the eastern seaboard cities performing similarly among the different co-benefits.

\section{Sensitivity Analysis}

A sensitivity analysis was executed to identify the influence of each i-Tree model input on the co-benefits. Non-linear interactions were included in the sensitivity analysis to sum the total of first order sensitivity indices of to one.

The vast majority of the co-benefits' sensitivity indices were dominated by DBH and non-linear interactions (Figure 4). Other model inputs such as Crown Missing and Crown Health have some sensitivity importance to the co-benefits of $\mathrm{PM}_{2.5}$ removal and Carbon sequestration, respectfully. However, DBH and non-linear interactions consistently had the greatest sensitivity indices (Figure 4; Appendix G). 


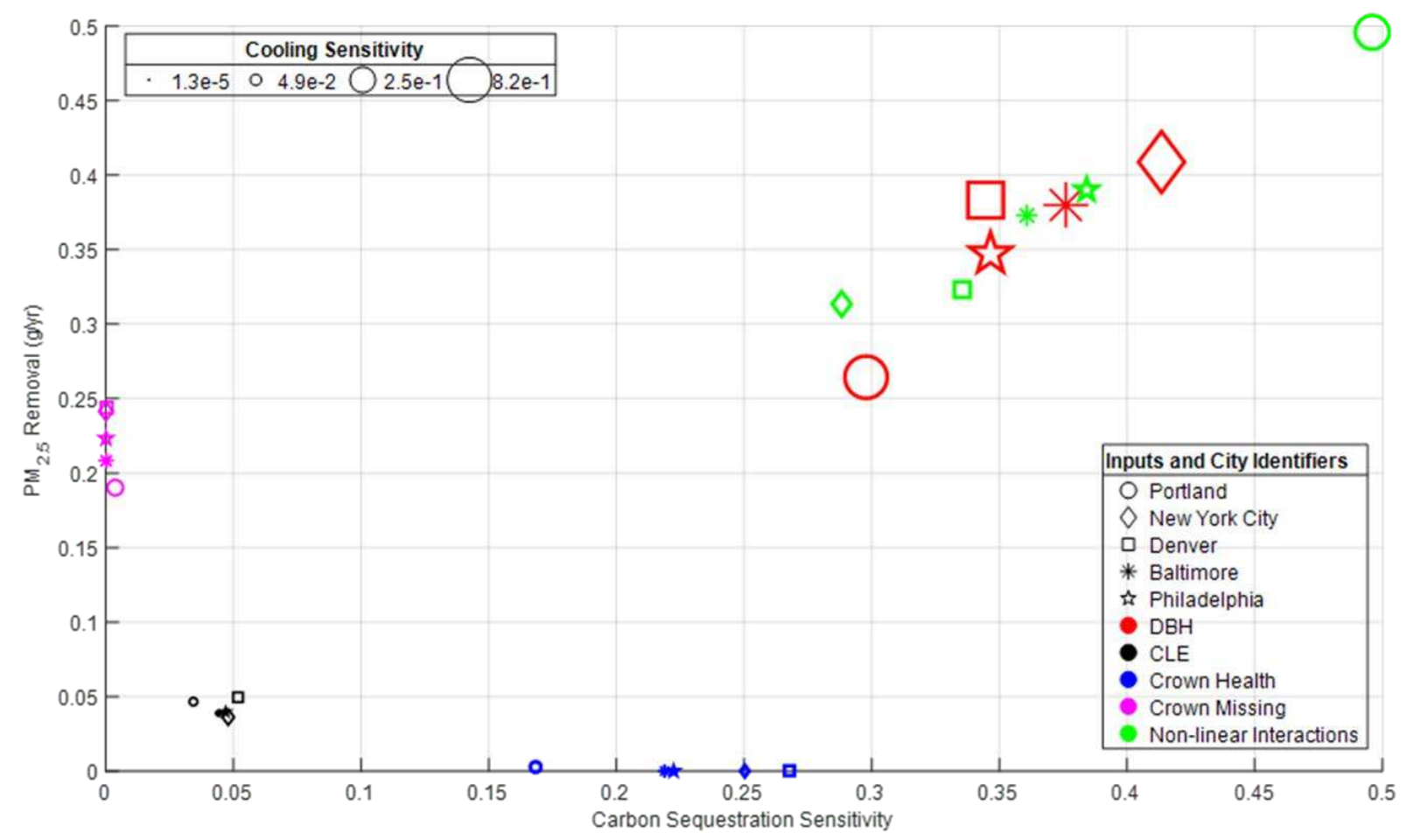

Figure 4: First Order Sensitivity Indices' of Model Inputs DBH, CLE, Crown Health, Crown Missing and Non-linear Interactions of Cooling, PM 2.5 removal, and Carbon sequestration for Portland, New York City, Baltimore, Denver, and Philadelphia 


\section{DISCUSSION}

\section{Design}

Denver, unlike other cities, had many extended detention areas as part of its SGI program with a larger number of trees that could to be planted. Further, the i-Tree model predicts more co-benefits when there were more trees. Denver had the largest tree inventory due to its emphasis on larger scale SGI, which led to large amounts of co-benefits. Therefore, the model also showed that Denver's SGI provided more benefits on the municipal scale despite having some of the least amount of co-benefits on the individual tree.

Since tree composition, size and growth also had an impact on the number of co-benefits provided, Portland performed better than Denver for some select co-benefits on the municipal scale. For instance, the USFS has shown that larger trees provide more shading for cooling and larger canopies with higher leaf-area improves air quality than smaller trees (Southern Center for Urban Forest Research, 2004).

\section{Individual SGI Co-benefits}

Trees grow at varying rates across biomes and the literature on the i-Tree model suggested it accounts for differences in growth and size for each species in each place. Therefore, we analyzed benefits provided by one tree species that exists in SGI projects across all the cities. Our results indicated that the i-Tree model indeed produces different responses in cities located in different biomes. This analysis shows how the model produces diverse outcomes in response to varying regional conditions.

Other studies have also shown that co-benefits are a function of the environmental and regional conditions in different cities. In particular, research has indicated that air pollutant removal may be sensitive to environmental variables (Hirabayashi et al., 2011). In our analysis, there were clear 
difference among cities in different climate regions. The model predicted that in Denver, an arid city, trees removed less $\mathrm{PM}_{2.5}$ and had lower carbon sequestration than trees in more humid regions, like the eastern seaboard and Portland.

Similarly, the i-Tree model predicted that Denver did not perform as well as the temperate cities when accounting for cooling benefits and energy savings. Meanwhile, other studies have shown that arid cities' vegetation can provide more cooling benefits than humid cities (Yu et al., 2018), and that humid cities might not actually experience the energy related benefits predicted by the i-Tree model (Nelson et al. 2012). Furthermore, there is growing evidence along the Front Range of Colorado, that trees provide significant cooling benefits in semi-arid environments (McHale et al., unpublished data). These contradictory results indicate that what the i-Tree model predicts in terms of co-benefits for these SGI projects, may not be an accurate representation of the total ecosystem services provided in each city.

\section{Sensitivity Analysis}

The final component of our study, the sensitivity analysis, showed that non-linear interactions play a significant role in the predictions of co-benefits by the i-Tree model. We defined Non-linear interactions as the internal i-Tree model mechanisms that are separate of the tree parameter inputs, such as local environmental factors from meteorological and pollution data for each study city. In fact, these non-linear interactions had the greatest influence on the co-benefits provided by trees in SGI. Thus, the growth of the tree and the internal mechanisms of i-Tree, climatic inputs and other local environmental factors, had the biggest influence on the evaluation of co-benefits of SGI. Similar sensitivity studies have showed that DBH plays a dominant role for both carbon storage and sequestration (Lin et al., 2020). Age and carbon storage had a non-linear relationship because DBHbased allometric equations that calculate carbon-based benefits per tree have non-linear responses due 
to variable tree growth along a tree's lifespan (Jucker et al., 2017). Studies have shown that the effect tree age has on co-benefits' value is species dependent and varies based on climate (Rötzer et al., 2019).

Other i-Tree Eco sensitivity analysis work showed that meteorological inputs have large impacts on the evaluation of air pollutant removal co-benefits (Hirabayashi et al., 2011; Lin et al., 2020). Studies have shown that air pollution removal increases to meteorological inputs such as temperature and photosynthetically active radiation, a measure of light available for photosynthesis (McCree, 1971), in a convex (non-linear) manner(Lin et al., 2020). Meteorological and environmental conditions outside the scope of this analysis can describe the non-linear forces that affect the values of air pollutant removal co-benefits. 


\section{CONCLUSION}

The aggregation of trees utilized in SGI designs among the different cities showed that the implementation of larger scale SGI technologies led to more trees being planted in SGI. Cities like Denver which used larger scale SGI technologies, provided more total amount of co-benefits than other cities. However, Portland provided more co-benefits than Denver in some co-benefit categories with less amounts of SGI trees, suggesting that tree population isn't the only factor for most amount of total cobenefits provided by the total tree population used in each city's SGI program.

Despite modelling the same tree species in four cities, within varying climate regions, there were differences in the evaluation of co-benefits. Climate seems to play a big role in determining the response for co-benefits between cities, as well as other environmental factors. There seems to be some regionality in the model as well with similar responses for the eastern seaboard cities.

Then, the sensitivity analysis consistently exhibits that the inputs that represent the tree growth and environmental factors heavily influence the evaluation of all co-benefits. Other work has shown that these factors have significant influence on the internal workings of i-Tree Eco. These findings can provide a promising step forward in learning more about the mechanisms and prevailing equations within i-Tree Eco, including factors that change with climate.

Overall, managers and researchers of SGI can utilize the findings of this study to inform decisions on providing SGI with the most co-benefits. The main purpose of SGI is to provide water storage and water quality benefits, however the co-benefit analysis outlined in this paper can be used for supplementary analysis to show more positive effects from the infrastructure interventions. This paper utilized a popular urban forestry model, i-Tree Eco, to model co-benefits based on the number of 
trees present in city SGI programs. These results can be used to develop more detailed benefits of the existing SGI as well as inform decisions.

When developing a SGI program, some factors should be noted to predict the amount of cobenefits. Factors include the number of technologies in the SGI program and what type of technologies are used, which determine how many trees there are based on the existing inventory and the size of the technologies. The type of climate is important as well because it indicates how the SGI trees will perform for some climate sensitive co-benefits. Lastly, it is crucial to note the maturity level of existing SGI trees as age is an important indicator of co-benefit evaluation.

Future studies can expand on this work by looking at other cities' that use trees in their SGI plans to test the theory that regionality exists in the model in areas other than the eastern seaboard. More analysis is needed to find the factors that result in exact correlation in co-benefit predictions between similar climate regions. Changes in co-benefits coming from the growth of trees over time were not included in this analysis, although it is an emerging field and exists in a limited capacity in iTree. Adding tree growth would enhance the co-benefits provided by trees across its lifetime and not give just a snapshot of co-benefits. 


\section{BIBLIOGRAPHY}

Alves, A., Gersonius, B., Kapelan, Z., Vojinovic, Z., Sanchez, A., 2019. Assessing the Co-Benefits of greenblue-grey infrastructure for sustainable urban flood risk management. J. Environ. Manage. 239, 244-254. https://doi.org/10.1016/j.jenvman.2019.03.036

Baltimore, C. of, 2018. Baltimore Building Footprints.

Baltimore, C. of, 2013. Baltimore City MS4 Restoration And TMDL WIP.

Bell, C.D., 2020. Denver Tree Spatial Datasets.

Choat, B., 2020. GSI Spatial Datasets for Baltimore and Portland.

City of New York, 2020. New York City Building Footprints.

City of Philadelphia Planning and Research, 2020. Philly Open Data: Building Footprints.

City of Philadelphia Planning and Research, City of Philadelphia Water Department, 2014. Stormwater Management Guidance Manual.

City of Philadelphia Water Department, 2020. Philly Open Data: GSI Datasets.

City of Portland, 2020. City of Portland Building Footprints.

City of Portland, 2017. Street Tree Inventory Report.

City of Portland, 2016. Stormwater Management Manual.

Corfee-Morlot, S.H.J., 2011. Understanding climate change impacts, vulnerability and adaptation at city scale : an introduction 1-12. https://doi.org/10.1007/s10584-010-9981-8

Coutts, C., Hahn, M., 2015. Green Infrastructure , Ecosystem Services, and Human Health 9768-9798. https://doi.org/10.3390/ijerph120809768

Daigger, G., Sharvelle, S., Arabi, M., Love, N., 2020. Progress and promise transitioning to the one water/resource recovery integrated urban water management systems. J. Environ. Eng.

Denver, T.C. and C. of, 2016. Ultra-Urban Green Infrastructure Guidelines. 
Duh, J., Shandas, V., Chang, H., George, L.A., 2008. Rates of urbanisation and the resiliency of air and water quality. Sci. Total Environ. 400, 238-256. https://doi.org/10.1016/j.scitotenv.2008.05.002 ESRI, 2019. ArcGIS Desktop Release 10.

EU Science Hub, 2008. SimLab 2.2 Reference Manual.

Forest Service, 2020. i-Tree Eco User's Manual.

Foster, J., Lowe, A., Winkelman, S., 2011. THE VALUE OF GREEN INFRASTRUCTURE FOR URBAN CLIMATE ADAPTATION.

Gallet, D., Grant, J., 2010. The Value of Green Infrastructure. CNT.

Grimm, N.B., Faeth, S.H., Golubiewski, N.E., Redman, C.L., Wu, J., Bai, X., Briggs, J.M., 2008. Global Change and the Ecology of Cities 756. https://doi.org/10.1126/science.1150195

Hammer, J., Pivo, G., 2016. The Triple Bottom Line and Sustainable Economic Development Theory and Practice. https://doi.org/10.1177/0891242416674808

Heisler, G., Grant, R., 2000. Ultraviolet Radiation, Human Health and the Urban Forest.

Hirabayashi, S., Kroll, C.N., Nowak, D.J., 2015. i-Tree Eco Dry Deposition Model Descriptions.

Hirabayashi, S., Kroll, C.N., Nowak, D.J., 2011. Environmental Modelling \& Software Component-based development and sensitivity analyses of an air pollutant dry deposition model. Environ. Model. Softw. 26, 804-816. https://doi.org/10.1016/j.envsoft.2010.11.007

Jayasooriya, V.M., Ng, A.W.M., Muthukumaran, S., Perera, B.J.C., 2017. Urban Forestry \& Urban Greening Green infrastructure practices for improvement of urban air quality $21,34-47$. https://doi.org/10.1016/j.ufug.2016.11.007 Jim, C.Y., Lo, A.Y., Byrne, J., 2015. Charting the green and climate-adaptive city. Landsc. Urban Plan. 5153.

Jo, H.K., McPherson, E.G., 1995. Carbon storage and flux in urban residential greenspace. J. Environ. Manage. https://doi.org/10.1006/jema.1995.0062 
Jucker, T., Caspersen, J., Chave, J., 2017. Allometric equations for integrating remote sensing imagery into forest monitoring programmes 177-190. https://doi.org/10.1111/gcb.13388

Kim, G., Miller, P.A., Nowak, D.J., 2015. Assessing urban vacant land ecosystem services : Urban vacant land as green infrastructure in the City of Roanoke, Virginia. Urban For. Urban Green. 14, 519-526. https://doi.org/10.1016/j.ufug.2015.05.003

Lhotka, J.M., Loewenstein, E.F., 2011. Forest Ecology and Management An individual-tree diameter growth model for managed uneven-aged oak-shortleaf pine stands in the Ozark Highlands of Missouri , USA. For. Ecol. Manage. 261, 770-778. https://doi.org/10.1016/j.foreco.2010.12.008

Lin, J., Kroll, C.N., Nowak, D.J., 2020. Ecosystem service-based sensitivity analyses of i-Tree Eco. Arboric. Urban For.

Litvak, E., Mccarthy, H.R., Pataki, D.E., 2012. Transpiration sensitivity of urban trees in a semi-arid climate is constrained by xylem vulnerability to cavitation $373-388$. https://doi.org/10.1093/treephys/tps015

Livesley, S.J., Mcpherson, E.G., Calfapietra, C., 2016. The Urban Forest and Ecosystem Services: Impacts on Urban Water, Heat, and Pollution Cycles at the Tree, Street, and City Scale 124, 119-124. https://doi.org/10.2134/jeq2015.11.0567

Maitner, B.S., Boyle, B., Casler, N., Condit, R., Donoghue, J., Sandra, I.I., Daniel, M.D., Cody, G., Jørgensen, P.M., Kraft, N.J.B., Mcgill, B., Merow, C., Morueta-holme, N., Smith, S.A., Peet, R.K., Sandel, B., Schildhauer, M., Barbara, J.S., Cyrille, T., 2018. The BIEN R package : A tool to access the Botanical Information and Ecology Network (BIEN ) database 2018, 373-379. https://doi.org/10.1111/2041-210X.12861

Marino, S., Hogue, I.B., Ray, C.J., Kirschner, D.E., 2009. A Methodology For Performing Global Uncertainty And Sensitivity Analysis In Systems Biology. https://doi.org/10.1016/j.jtbi.2008.04.011.A 
Mathworks Inc., 2017. Matlab 2020.

Mccarthy, H.R., Pataki, D.E., Jenerette, G.D., 2011. Plant water-use efficiency as a metric of urban ecosystem services. Ecol. Soc. Am. 21, 3115-3127.

McCree, K.J., 1971. TEST OF CURRENT DEFINITIONS OF PHOTOSYNTHETICALLY ACTIVE RADIATION AGAINST LEAF PHOTOSYNTHESIS DATA. Company, Elsevier Publ.

Mcpherson, E.G., Grimmond, S.U.E., Souch, C., 1997. Quantifying urban forest structure , function , and value : the Chicago Urban Forest Climate Project 49-61.

Mcpherson, E.G., Maco, S.E., Simpson, J.R., Peper, P.J., 2002. Western Washington and Oregon Community Tree Guide : Benefits, Costs and by.

McPherson, E.G., Mori, S.M., 1998. Equations for predicting diameter, height, crown width and leaf are of San Joaquin Valley Street Trees 306-317.

McPherson, E.G., Simpson, J.R., 1999. Carbon Dioxide Reduction Through Urban Forestry : Guidelines for Professional and Volunteer Tree Planters.

Mcpherson, E.G., Simpson, J.R., Peper, P.J., 2006. Piedmont Community Tree Guide.

Mcpherson, E.G., Simpson, J.R., Peper, P.J., Maco, S.E., 2007. Northeast Community Tree Guide.

Mcpherson, E.G., Simpson, J.R., Peper, P.J., Maco, S.E., 2003. Northern Mountain and Prairie Community Tree Guide Benefits.

Meerow, S., Newell, J.P., 2017. Spatial planning for multifunctional green infrastructure: Growing resilience in Detroit. Landsc. Urban Plan. 159, 62-75.

https://doi.org/10.1016/j.landurbplan.2016.10.005

Mentens, J., Raes, D., Hermy, M., 2006. Green roofs as a tool for solving the rainwater runoff problem in the urbanized 21st century ? Landsc. Urban Plan. 77, 217-226.

https://doi.org/10.1016/j.landurbplan.2005.02.010

Neumann, J.E., Price, J., Chinowsky, P., Wright, L., Ludwig, L., Streeter, R., Jones, R., Smith, J.B., Perkins, 
W., Jantarasami, L., Martinich, J., 2015. Climate change risks to US infrastructure : impacts on roads , bridges , coastal development , and urban drainage 97-109. https://doi.org/10.1007/s10584-0131037-4

Nowak, D., 2010. Urban Biodiversity and Climate Change, Urban Biodiversity and Design.

Nowak, D.J., 2016. The Urban Forest of Philadelphia.

Nowak, D.J., 2000. The interactions between urban forests and global climate change. For. Serv.

Nowak, D.J., Crane, D.E., 2000. The Urban Forest Effects (UFORE) Model: Quantifying Urban Forest Structure and Functions.

Nowak, D.J., Crane, D.E., Stevens, J.C., 2006. Air pollution removal by urban trees and shrubs in the United States 4. https://doi.org/10.1016/j.ufug.2006.01.007

Nowak, D.J., Crane, D.E., Stevens, J.C., Hoehn, R.E., Walton, J.T., 2008a. A Ground-Based Method of Assessing Urban Forest Structure and Ecosystem Services 34, 347-358.

Nowak, D.J., Crane, D.E., Stevens, J.C., Ibarra, M., 2000. Brooklyn's Urban Forest.

Nowak, D.J., Green, E.J., Hoehn, R.E., Lapoint, E., 2013. Carbon storage and sequestration by trees in urban and community areas of the United States 178.

https://doi.org/10.1016/j.envpol.2013.03.019

Nowak, D.J., Walton, J.T., Stevens, J.C., Crane, D.E., Hoehn, R.E., 2008b. Effect of Plot and Sample Size on Timing and Precision of Urban Forest Assessments 34, 386-390.

NYCDEP, 2018a. NYC DEP GI Tree Data.

NYCDEP, 2018b. New York City GSI Spatial Datasets.

NYCDEP, 2013. Standards for Green Infrastructure.

Peng, L.L.H., Jim, C.Y., 2015. Economic evaluation of green-roof environmental benefits in the context of climate change : The case of Hong Kong. Urban For. Urban Green. 14, 554-561.

https://doi.org/10.1016/j.ufug.2015.05.006 
Philadelphia Water Department, 2020. PWD Frequency Table.

Philadelphia Water Department, 2018. Stormwater Infrastructure Landscape Design Guidebook 154.

Porse, E.C., 2013. Stormwater Governance and Future Cities 29-52. https://doi.org/10.3390/w5010029

Portland, C., 2010. Portland's Green Infrastructure: Quantifying the Health, Energy and Community Livability Benefits. Strateg. Pap. 1-101.

Portland Parks \& Recreation, 2020. Tree Inventory Project [WWW Document]. City Portl.

Rosenzweig, C., Solecki, W.D., Blake, R., Bowman, M., Faris, C., Gornitz, V., Horton, R., Jacob, K., Leblanc, A., Leichenko, R., Linkin, M., Major, D., Grady, M.O., Patrick, L., Sussman, E., Yohe, G., Zimmerman, R., 2011. Developing coastal adaptation to climate change in the New York City infrastructureshed : process , approach , tools, and strategies 93-127. https://doi.org/10.1007/s10584-010$0002-8$

Rötzer, T., Rahman, M.A., Moser-reischl, A., Pauleit, S., Pretzsch, H., 2019. Science of the Total Environment Process based simulation of tree growth and ecosystem services of urban trees under present and future climate conditions. Sci. Total Environ. 676, 651-664. https://doi.org/10.1016/j.scitotenv.2019.04.235

Ryeol, H., Heisler, G.M., Nowak, D.J., Grant, R.H., 2014. Urban Forestry \& Urban Greening Modeling of urban trees ' effects on reducing human exposure to UV radiation in Seoul, Korea. Urban For. Urban Green. 13, 785-792. https://doi.org/10.1016/j.ufug.2014.05.009

Saltelli, A., 2008. Global Sensitivity Analysis: The Primer.

Sanusi, R., Johnstone, D., May, P., Livesley, S.J., 2017. Microclimate benefits that different street tree species provide to sidewalk pedestrians relate to differences in Plant Area Index. Landsc. Urban Plan. 157, 502-511. https://doi.org/10.1016/j.landurbplan.2016.08.010

Shortle, J.S., Mihelcic, J.R., Zhang, Q., Arabi, M., 2020. Nutrient control in water bodies : A systems approach 517-533. https://doi.org/10.1002/jeq2.20022 
Southern Center for Urban Forest Research, 2004. The Large Tree Arguement. United States For. Serv.

Spahr, K.M., Bell, C.D., Mccray, J.E., Hogue, T.S., 2020. Greening up stormwater infrastructure :

Measuring vegetation to establish context and promote cobenefits in a diverse set of US cities.

Urban For. Urban Green. 48, 126548. https://doi.org/10.1016/j.ufug.2019.126548

Spatari, S., Yu, Z., Montalto, F.A., 2011. Life cycle implications of urban green infrastructure. Environ. Pollut. 159, 2174-2179. https://doi.org/10.1016/j.envpol.2011.01.015

Staddon, C., Ward, S., Vito, L. De, Zuniga, A., Andrea, T., Schoeman, Y., Hart, A., Booth, G., 2018. Contributions of green infrastructure to enhancing urban resilience. Environ. Syst. Decis. 38, 330338. https://doi.org/10.1007/s10669-018-9702-9

State, N.Y., 2010. Stormwater Management Design Manual.

State of Maryland, 2009a. Chapter 4 Maryland Stormwater Design Manual.

State of Maryland, 2009b. Appendix A: Maryland Stormwater Design Manual.

Stefanakis, A.I., 2019. The Role of Constructed Wetlands as Green Infrastructure for Sustainable Urban Water Management.

Tam, B.Y., Gough, W.A., Mohsin, T., 2015. The impact of urbanization and the urban heat island effect on day to day temperature variation. Urban Clim. 12, 1-10. https://doi.org/https://doi.org/10.1016/j.uclim.2014.12.004

Tasdighi, A., Arabi, M., Osmond, D.L., 2017. The Relationship between Land Use and Vulnerability to Nitrogen and Phosphorus Pollution in an Urban Watershed 113-122. https://doi.org/10.2134/jeq2016.06.0239

The City and County of Denver, 2020. Denver GSI Spatial Datasets.

The City and County of Denver, 2017. Approved Street Tree List for Denver's Public Right-of-way Trees. The City and County of Denver, 2016. Denver Building Outlines.

Tzoulas, K., Korpela, K., Venn, S., Yli-Pelkonen, V., Kaźmierczak, A., Niemela, J., James, P., 2007. 
Promoting ecosystem and human health in urban areas using Green Infrastructure: A literature review. Landsc. Urban Plan. 81, 167-178. https://doi.org/10.1016/j.landurbplan.2007.02.001 UESPA, 2020. What is Green Infrastructure? [WWW Document]. UESPA. URL https://www.epa.gov/green-infrastructure/what-green-infrastructure UMD, E.F.C., 2017. Holistically Analyzing the Benefits of Green Infrastructure. USEPA, 2013a. The Importance of Operation and Maintenance for the Long-Term Success of Green Infrastructure.

USEPA, 2013b. Case Studies Analyzing the Economic Benefits of Low Impact Development and Green Infrastructure Programs Case Studies Analyzing the Economic Benefits of Low Impact Development and Green Infrastructure Programs.

USEPA, 2006. The Sun, UV and You: A Guide to SunWise Behavior.

Vineyard, D., Ingwersen, W.W., Hawkins, T.R., Xue, X., Demeke, B., Shuster, W., 2015. COMPARING GREEN AND GREY INFRASTRUCTURE USING LIFE CYCLE COST AND ENVIRONMENTAL IMPACT : A RAIN GARDEN CASE STUDY IN CINCINNATI , OH 1. J. Am. Water Resour. Assoc. 51. https://doi.org/10.1111/1752-1688.12320

White, B.Y.J., 1998. Estimating the Age of Large and Veteran Trees in Britain. UK For. Comm. 1-8. Wise, S., Braden, J., Ghalayini, D., Grant, J., Kloss, C., Macmullan, E., Morse, S., 2010. Integrating Valuation Methods to Recognize Green Infrastructure 's Multiple Benefits 1123-1143.

World Health Organization, 2017. Ultraviolet (UV) Index [WWW Document]. World Heal. Organ. URL https://www.who.int/news-room/q-a-detail/ultraviolet-(uv)-index

Yang, J., McBride, J., Zhou, J., Sun, Z., 2005. The urban forest in Beijing and its role in air pollution reduction. Urban For. Urban Green. 3, 65-78. https://doi.org/https://doi.org/10.1016/j.ufug.2004.09.001

Young, R.F., Practices, B., Young, R.F., 2011. Infrastructure - Results From Major U . S . Cities. J. Am. 
Plan. Assoc. https://doi.org/10.1080/01944363.2011.616996

Yu, Z., Xu, S., Zhang, Y., Jørgensen, G., Vejre, H., 2018. Strong contributions of local background climate to the cooling effect of urban green vegetation 1-9. https://doi.org/10.1038/s41598-018-25296-w

Zhan, W., Fong, T., Chui, M., 2016. Evaluating the life cycle net benefit of low impact development in a city. Urban For. Urban Green. 20, 295-304. https://doi.org/10.1016/j.ufug.2016.09.006 